is little or no hope of saving its sight. If its effects were brought home to the future fathers and mothers of the nation of every class it would help to remove the scourge.

The following took part in the discussion on this paper:-Dr. C.S. Thompson (Hyde); Mrs. E. Fulller (Dover) ; Mr. T. E. Butler (Leeds); Miss O'Riordan (Camberwell); Dr. Bostock Hill (Bembridge); Lady Borrowes (Folkestone); Mr. W. Boissonade (Acton); Miss F. Ames (Folkestone).

\title{
Common-Sense Hygiene in the Home.
}

By Arthur F. Wicienden, A.M.Inst.C.E., A.R.I.B.A., P.A.S.I. (Member).

\section{(ABSTRACT.)}

A LTHOUGH the question of hygienic homes has been so much discussed $A$ for many years past, the practical results from the great attention rightly given to the subject are not so apparent in the average homes of the community as could be desired.

The lack of essential co-operation on the part of the masses may be partly attributed to the fact that hygienic subjects are too frequently placed before the public in such theoretical and idealistic forms that they appear impractical.

In this short paper a few suggestions are put forward relative to the construction and furnishing of common-place houses.

Giving first consideration to constructional matters, the question of floors calls for attention.

Many excellent types of jointless composition flooring are now available, which are to be strongly recommended in preference to the usual boarded floors. A room covered with jointless flooring, polished if desired, and furnished with rugs of various sizes, placed where required, so as to be easily taken up for shaking, can be made quite comfortable, and kept infinitely cleaner than one covered wholly or partially by one large carpet, which quickly becomes dust-laden, in spite of modern mechanical carpet-sweepers of varying degrees of efficiency.

The latest types of steel windows show a great advance over the oldfashioned timber casements, or sashes and frames, as regards the admission 
of the maximum quantity of light, prevention of draughts and convenience of adjustment to allow adequate ventilation.

Efficient ventilation of the living rooms of ordinary houses, independently of window openings, is a matter to which more attention might well be given, and the provision of fresh air inlets and foul air extracts would add considerably to the comfort and health of the inmates of such houses.

The usual sanitary fittings in small houses very often leave much to be desired in matters of design, construction, quality and methods of fixing.

The treatment of wall surfaces is an important factor in the sanitary home. For decorative purposes the use of washable paint has much to recommend it in preference to wall-papers, and there appears to be no valid reason why picture rails should not be fixed considerably lower than customary, so as to be within easy reach for dusting and by allowing a deeper frieze, finished in white or light tints, to assist in the reflection of light.

From the points of view of economy and cleanliness it will probably be agreed that gas should be employed for cooking and heating, but more attention should be directed to the improvement of the hygienic properties of gas-cooking stoves.

In the furnishing of the majority of homes of the poorer and middleclasses traditional customs and habits are too frequently followed with a disregard of common-sense hygienic principles.

The reforms urged include the reduction of all furniture, curtains. floor coverings and ornaments to a minimum compatible with comfort and a pleasing appearance.

The use is suggested of well designed and strongly-made wooden furniture with detachable seat and back cushions in preference to the heavily upholstered productions, in the cheaper varieties of which sanitary construction is extremely problematical, while their presence in the house is certainly not conducive to cleanliness.

In conclusion it is claimed that the simple hygienic home, while promoting clean and healthy living, can be made perfectly comfortable, and is also a sound economic proposition.

The folloreing took part in the discussion on this paper:-Dr. C. S. Thompson (Hyde); Miss L. Harvey (Folkestone); Ald. J. H. Dobson (Tottenham); Dr. T. W. N. Barlow (Wallasey) ; Mr. D. Pugh-Jones (Cardiff) ; Mr. Fletcher. 